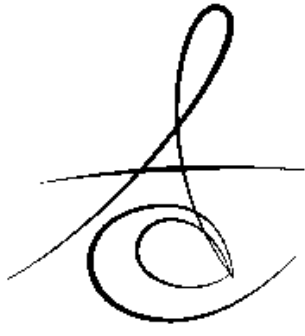

Makale Kodu/Article code: 1782

Makale Gönderilme tarihi: 17.07.2014

Kabul Tarihi: 02.10.2014

\title{
MAKSİLLER SİNÜSTE EKTOPİK DİŞLE İLIŞ̧K̇̇İ DENTİGERÖZ KİST: OLGU SUNUMU
}

\section{DENTIGEROUS CYST ASSOCIATED WITH AN ECTOPIC TOOTH IN THE MAXILLARY SINUS: A CASE REPORT}

Yrd. Doç. Dr. Adnan KILINÇ*

Arş. Gör. Dt. Tahsin TEPECİK*

\section{ÖZET}

Amaç: Maksiller sinüste ektopik diş nadir görülmektedir. Odontojenik gelişimsel bir anomali olarak görüldüğünde genellikle odontojenik kist, travma veya iyatrojenik etyolojiyle ilişkilidir. Bu vaka raporunun amacı, maksiller sinüste ektopik yirmi yaş dişi ile ilişkili dentigeröz kistin Caldwell Luc ameliyatı ile enükleasyonunu sunmaktır.

Gereç ve Yöntem: Yapılan klinik ve radyolojik incelemeler sonucunda 25 yaşında erkek hastanın sağ maksiller sinüsünde ektopik yirmi yaş dişi ile ilişkili dentigeröz kist tespit edildi. Caldwell-Luc ameliyatı ile maksiller sinüs içerisindeki ektopik diş çıkartılarak dentigeröz kist enükle edildi.

Bulgular: Radyolojik ve klinik olarak takibi devam eden hastada perioperatif ve postoperatif olarak herhangi bir komplikasyonla karşılaşılmadı.

Sonuç: Maksiller sinüste bulunan ektopik dişle ilişkili dentigeröz kistlerin enükleasyonunda Caldwell Luc ameliyatı güvenli, minimal komplikasyonlu, basit, hızlı ve sık kullanılan başarılı bir yöntemdir.

Anahtar Kelimeler: Maksiller sinüs, azı dişi

\section{GİRIş}

Diş gelişimi, oral epitelyal ve mezenkimal doku arasında çok aşamalı karmaşık bir etkileşim sonucu meydana gelmektedir. Bir dizi kompleks doku etkileşimi sonucunda da olgun diş oluşmaktadır. Diş gelişimi sırasında anormal doku etkileşimleri ektopik diş ve sürmelere neden olabilir. ${ }^{1}$ Ektopik diş; gelişimsel bozukluk, iyatrojenik, tümör veya patolojik nedenlerden dolayı gelişmektedir. ${ }^{2,3}$ Dental yapılar içerisinde dişin ektopik sürmesi yaygın olmasına rağmen diğer bölgelerde ektopik diş görülmesi nadirdir. ${ }^{4}$ Dental

\section{ABSTRACT}

Purpose: Ectopic tooth in the maxillary sinus is rare. When seen as an odontogenic developmental anomaly; often is associated with odontogenic cysts, trauma or iatrogenic etiology. The aim of this case report to present enucleation of dentigerous cyst associated with ectopic wisdom tooth from maxillary sinus with Caldwell Luc surgery.

Material and Method: At the result of the clinical and radiological findings, ectopic wisdom tooth along with dentigerous cyst was found in the right maxillary sinus in a 25 year old male patient. Ectopic tooth in maxillary sinus was removed and dentigerous cyst was enucleated with Caldwell-Luc surgery.

Results: Radiological and clinical follow-up perioperative or postoperative complications were not seen.

Conclusion: Caldwell Luc surgery is safe, minimally complicated, simple, quick and successful method for enucleation of dentigerous cyst associated with ectopic tooth in the maxillary sinus.

Key Words: Maxillary sinus, molar tooth

yapılar dışında ektopik dişin görüldüğü yerlerden biri de maksiller sinüslerdir. ${ }^{1}$ Maksiller sinüse veya infratemporal fossaya molar dişin yer değiştirmesi nadir görülen bir durumdur. ${ }^{5,6}$

Maksiller sinüs hastalıklarının tedavisinde Caldwell-Luc ameliyatı uzun yıllardır kullanılmaktadır. Caldwell-Luc ameliyatı 1893 yılında ilk kez George Caldwell tarafından tanımlandı, 1897 yılında da Henri Luc tarafından maksiller sinüs hastalıklarına cerrahi yaklaşım olarak kullanılmaya başlandı. ${ }^{7-9}$ Standart Caldwell-Luc ameliyatında, fossa kanina yoluyla maksiller sinüse girilir ve hastalıklı sinüs membranı

* Atatürk Üniversitesi, Diş Hekimliği Fakültesi, Ağız Diş ve Çene Cerrahisi A D 
çıkartıı. İnferior nazal meatusun lateral duvarından sinüs drenajını kolaylaştırmak için antrostomi yapılır ve genellikle geçici olarak tampon yerleştirilir. ${ }^{9-11}$ Bu vaka raporunda, 25 yaşında erkek hastanın sağ maksiller sinüsünde ektopik olarak bulunan yirmi yaş dişi ile ilişkili dentigeröz kistin Caldwell-Luc ameliyatı ile tedavisi sunulmaktadır.

\section{OLGU SUNUMU}

25 yaşında erkek hasta sağ maksiller bölgesinden yüzüne doğru vuran ağrı şikayeti ile kliniğimize başvurdu. Hastanın yapılan klinik muayenesinde intraoral olarak herhangi bir şişlik veya enfeksiyon belirtisi bulunmamaktaydı. Ekstraoral muayenesinde, yüzünde herhangi bir şişlik bulunmayan hastanın fossa kanina bölgesinde palpasyonda hassasiyet mevcuttu.

Yapılan radyolojik muayenedesinde; panoramik radyografide sağ maksiller sinüste dentigeröz kist ile birlikte ektopik yirmi yaş dişi olduğu görüldü (Şekil 1).

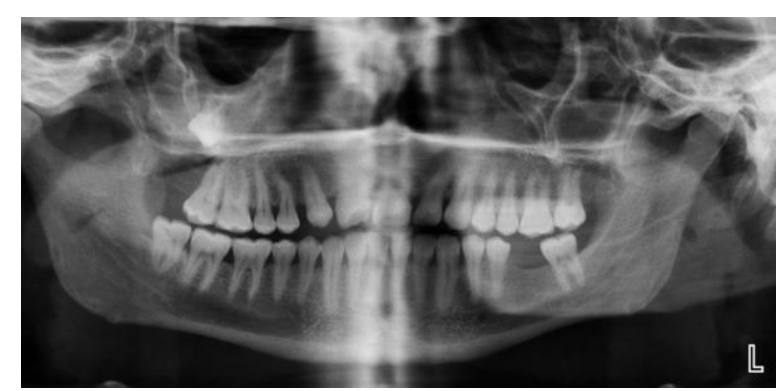

Şekil 1: Panoramik radyografide sağ maksiller sinüste lokalize ektopik yirmi yaş dişi görülmektedir.

Detaylı radyolojik inceleme için hastadan ConeBeam Computed Tomograpy (CBCT) alındı. CBCT maksillofasiyal (aksiyal) tomografi ve CBCT-Dental tomografik görüntülerde sağ maksiller 18 nolu dişin maksiller sinüs içerisinde gömük kaldığı, etrafında kistik lezyon geliştiği ve sinüste enflamatuar mukozal değişiklikler oluştuğu gözlenmiştir (Şekil 2).
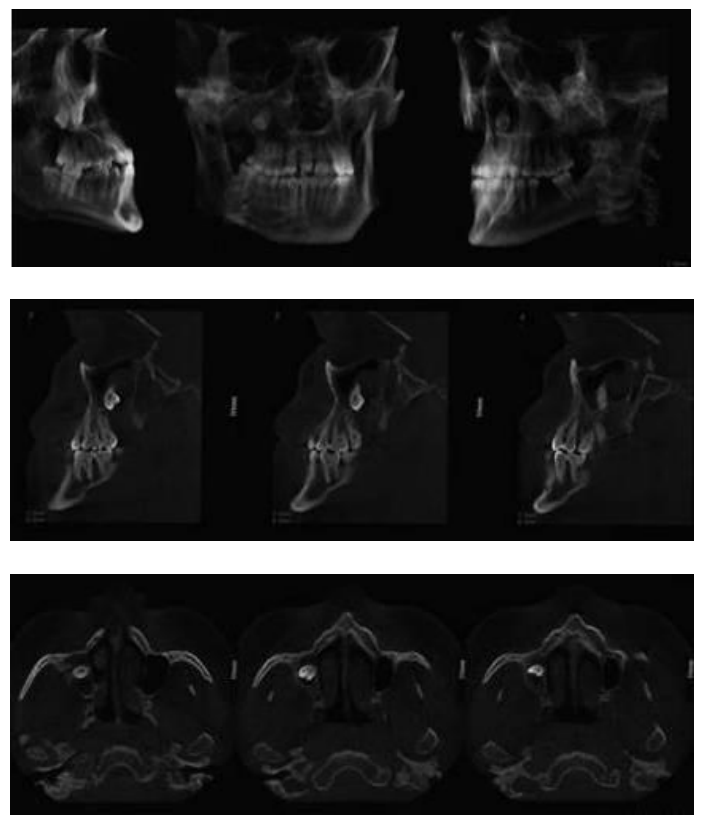

Şekil 2: CBCT görüntülerinde maksiller sinüste ektopik yirmiyaş dişi ile birlikte dentigeröz kist görülmektedir.

Lokal anestezi altında Caldwell-Luc ameliyatı ile maksiller sinüste bulunan ektopik yirmi yaş dişinin ve dentigeröz kistin alınmasına karar verildi. Bilgilendirme ve onam formu alınan hastaya lokal anestezi yapılarak kanin dişinden 1. molar dişe kadar vestibüler insizyon yapıldı. İnfraorbital sinir korunarak tam kalınlıklı flep kaldırıldı. Kanin ve küçük azı dişlerinin apeksinden 4-5 mm uzaktan olacak şekilde fossa kanina bölgesinden kemik penceresi açıldı (Şekil 3).

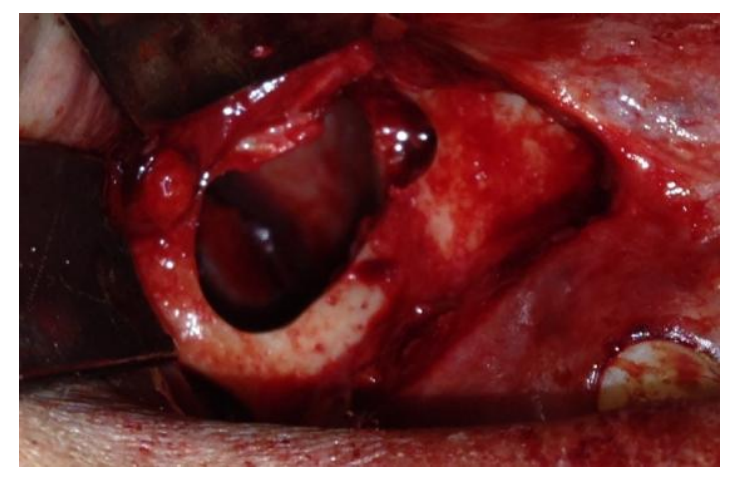

Şekil 3: Fossa kanina bölgesinden açılan kemik penceresi

İkinci büyük azı dişinin apeksinde lokalize olan ektopik yirmi yaş dişi çekildi, dişle ilişkili olan dentigeröz kist enükle edildi, Histopatolojik inceleme

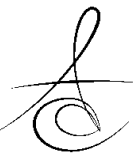


için spesimen 18/06/2014 tarihinde 5993-14 numarası ile Atatürk Üniversitesi Tıp Fakültesi Tıbbi Patoloji Bölüme gönderildi (Şekil 4).

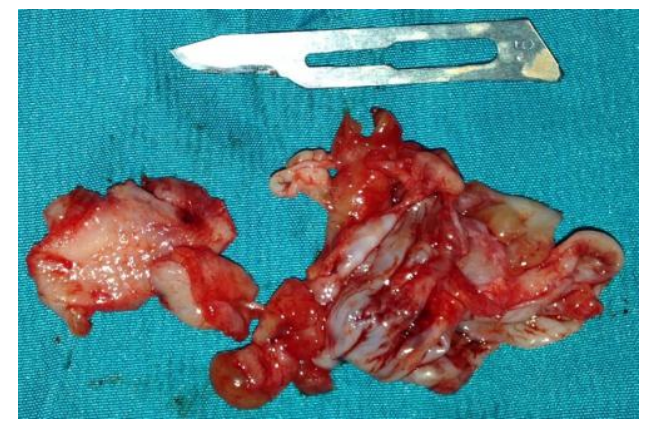

Şekil 4: Enükle edilen dentigeröz kist

Sinüs içi irige edildikten sonra inferior nazal meatustan antrostomi yapılarak sinüs tamponu yerleştirildi. Kanama kontrolü sağlanarak yara yerleri primer olarak sütüre edildi. 24 saat sonra tampon çıkartıldı. 1 hafta sonrasında hastanın sütürleri alındı. Histopatolojik olarak dentigeröz kist teşhisi konulan hastada perioperatif ve postoperatif olarak herhangi bir komplikasyonla karşılaşılmadı.

\section{TARTIŞMA}

Ektopik dişler, çene kemiklerinde veya alveolar ark dışındaki bölgelerde görülmektedirler. Dişlerin ektopik sürmesi nadir görülen bir durum olmakla birlikte; burunda, mandibular kondilde, koronoid proçeste ve paranasal sinüslerin en büyüğü olan maksiller sinüste görülen ektopik diş vakaları rapor edilmiştir. ${ }^{12}$ Vakamızda da üst yirmi yaş dişi ektopik olarak maksiler sinüste görülmekteydi.

Ektopik sürmenin etiyolojisi halen tam olarak bilinmemektedir, fakat travma, enfeksiyon, gelişimsel anomaliler ve dentigeröz kist gibi patolojik durumları içeren birçok teori ileri sürülmektedir. ${ }^{13}$ Vakamıza etyolojik olarak dentigeröz kistin neden olduğu düşünüldü.

Yirmi yaş dişleri genellikle gömüktür veya ektopik pozisyondadır. Ektopik lokalizasyonlardan biri de maksiller sinüslerdir. Maksiller sinüslerinin radyografik incelenmesinde, Waters sinüs grafisi uzun yıllar boyunca en sık kullanılan yöntem olarak kabul edilmiştir. Fakat günümüzde, modern görüntüleme yöntemleri Waters sinüs grafisi gibi konvansiyonel diğer tekniklerin yerini almaktadır. ${ }^{14-16}$ Genellikle maksiler sinüsteki ektopik dişler dentigeröz kistle ilişkilidir ve maksiller sinüsü kısmen veya tamamen doldurarak çeşitli semptomlara neden olmaktadırlar. Rutin radyografik kontrollerde teşhis edilirler ya da hastalar sinüsle ilişkili tipik klinik semptomlar verirler. 12, 17 Hastadan alınan panoramik radyografide sağ maksiller sinüsteki ektopik diş ile ilişkili dentigeröz kist teşhis edildi. Detaylı inceleme ve sınırların daha net belirlenebilmesi için hastadan $\mathrm{CBCT}$ alındı.

Dentigeröz kistler, en yaygın görülen foliküler kistlerdir. Hayatın 2. ve 3. dekatlarında özellikle de erkeklerde daha sık görülmektedir. Dentigeröz kistlerin yaklaşık olarak \%70'i mandibulada, $\% 30$ 'u ise maksillada görülmektedir. ${ }^{18}$ Vakamızda da literatüre uygun olarak 25 yaşında erkek hastada ve fakat maksillada görülmekteydi.

Dentigeröz kistin ayırııı tanısı, radiküler kist, odontojenik keratokist gibi odontojenik kistlerle; ameloblastoma, Pindborg tümörü, odontoma, odontojenik fibroma ve sementoma gibi odontojenik tümörlerle yapılmalıdı. ${ }^{19,}{ }^{20}$ Ayırıcı tanının yapılabilmesi için spesimen histopatolojik incelemeye gönderildi.

Dentigeröz kistin standart tedavisi enükleasyon ve kistle ilişkili gömük dişin çıkartılmasıdır. ${ }^{19,} 21,22$ Geniş kistlerde, osseöz defektin boyutlarını azaltmak için başlangıçta marsüpyalizasyon yapılması, sonrasında enükleasyon ile birlikte dişin çekimi savunulmaktadır. ${ }^{22,}{ }^{23} \mathrm{CBCT}$ görüntülerinde çok geniş sınırlara ulaşmadığı görülen kistin marsüpyalizasyon yapılmadan enükleasyonu planlanarak ektopik diş çıkartılarak kist enükle edildi.

Maksiller sinüsteki dentigeröz kistle birlikte görülen ektopik dişler genellikle Caldwelll-Luc ameliyatı ile kolaylıkla çıkartılır. ${ }^{23}$ Endoskopik tekniğin başarısına rağmen Caldwell-Luc ameliyatının halen geniş bir endikasyonu bulunmaktadır. Bunlar; sinüs içindeki kist ve tümörler, yabancı cisimler, oroantral fistül, maksiller osteonekroz, epistaksis kontrolü, irreversibl mukozal değişikliğin olduğu sinüzit, mikotik fungal birikimler ve fasiyal travmadır. ${ }^{7,9,24,25}$ Standart Caldwell-Luc ameliyatının komplikasyonları; yüzde şişlik (\%90), yanakta ağrı (\%33), ateş (\%12), hemoraji, fasiyal asimetri, fasiyal parestezi, oroantral fistül, dakriyosistit, dişlerin devital olması, rekürrent polip ve rekürrent sinüzittir. ${ }^{24}$ Vakamızda standart Caldwell Luc ameliyatı uygulandı, perioperatif veya postoperatif olarak herhangi bir komplikasyonla karşılaşılmadı. 
Maksiller sinüste; direnaj için $\% 80$ oranında medial duvarın süperiorunda lokalize olan ostium bulunmaktadır. Birçok hastada mukozal kalınlaşmadan dolayı daha çok kanal benzeri şekildedir. Genellikle nazal kaviteyi ethmoid infundibuluma bağlar. Sinüs drenajı öncelikle siliar hareketle sağlanır. Bu siliar hareket oldukça etkilidir. Bir vaka raporunda, drenaj için cerrahi olarak inferior açıklık yapılsa da siliar aktivitenin sinüsü süperiora doğru başarıı bir şekilde temizleyebildiğini göstermektedir. ${ }^{26} 1941^{\prime}$ de Hilding tavşanlarda sinüsün farklı bölgelerinde oluşturulan antral pencerelerle ilgili bir dizi deney gerçekleştirdi. Bu çalışma, tavşanlarda maksiller sinüsün doğal ostiumda ya da yakınında uygulanan operatif prosedürleri tolere edemediğini, ancak doğal ostiumdan uzak yapıldığında oldukça iyi tolere etmekte olduğunu göstermektedir. ${ }^{27}$ Bu çalışmanın bir sonucu olarak, doğal ostiumdan uzak uygulanan cerrahi prosedürü kabul edildi ve inferior meatal antrostomi büyük ölçüde kabul edildi. ${ }^{10}$ Literatüre uygun olarak, bu vaka raporunda da ektopik yirmi yaş dişi ve dentigeröz kist Caldwell-Luc ameliyatıyla çıkartılarak inferior meatal anstrostomi yapıldı.

Sonuç olarak; maksiller sinüsteki ektopik dişlerin tedavisi genellikle çıkartımasıdır çünkü tedavi edilmeden bırakılan dişlerde kistik veya tümoral dokular gelişebilmekte ve bu lezyonlar da orbita tabanı perforasyonuna ve nazal kavite tıkanıklıklarına neden olabilmektedir. Maksiller sinüste ektopik olarak bulunan dişle ilişkili dentigeröz kistlerin cerrahi olarak çıkartılmasında da Caldwell-Luc ameliyatı etkili, güvenli ve başarılı olmakla birlikte günümüzde de halen en çok kullanılan yöntemlerden biridir.

\section{KAYNAKLAR}

1. Goh YH. Ectopic eruption of maxillary molar tooth-an unusual cause of recurrent sinusitis. Singapore medical journal 2001;42:80-1.

2. Srinivasa Prasad T, Sujatha G, Niazi TM, Rajesh P. Dentigerous cyst associated with an ectopic third molar in the maxillary sinus: a rare entity. Indian Journal of Dental Research 2007;18:141.

3. Bodner L, Tovi F, Bar-Ziv J. Teeth in the maxillary sinus-imaging and management. The Journal of laryngology and otology 1997;111:820-4.

4. Elango S, Palaniappan SP. Ectopic tooth in the roof of the maxillary sinus. Ear, nose, \& throat journal 1991;70:365-6.
5.

6. Dimitrakopoulos I, Papadaki M. Displacement of a maxillary third molar into the infratemporal fossa: case report. Quintessence international 2007;38:607-10.

7. Oberman M, Horowitz I, Ramon Y. Accidental displacement of impacted maxillary third molars. International journal of oral and maxillofacial surgery 1986;15:756-8.

8. Barzilai $G$, Greenberg $E$, Uri N. Indications for the Caldwell-Luc approach in the endoscopic era. Otolaryngology--head and neck surgery : official journal of American Academy of OtolaryngologyHead and Neck Surgery 2005;132:219-20.

9. Tange RA. Some historical aspects of the surgical treatment of the infected maxillary sinus. Rhinology 1991;29:155-62.

10. Matheny KE, Duncavage JA. Contemporary indications for the Caldwell-Luc procedure. Current opinion in otolaryngology \& head and neck surgery 2003;11:23-6.

11. Al-Belasy FA. Inferior meatal antrostomy: is it necessary after radical sinus surgery through the Caldwell-Luc approach? Journal of oral and maxillofacial surgery : official journal of the American Association of Oral and Maxillofacial Surgeons 2004;62:559-62.

12. Brook I. Sinusitis: From Microbiology to Management: CRC Press; 2005.

13. Amin ZA AM, Khairudin. . Removal of extensive maxillary dentigerous cyst via a Caldwell-Luc procedure. Arch Orofac Sci 2008;3: 48-51.

14. Büyükkurt M, Tozoglu S, Aras M, Yolcu U. Ectopic eruption of a maxillary third molar tooth in the maxillary sinus: a case report. J Contemp Dent Pract 2005;6:104-10.

15. Sümbüllü MA, Çakur B, Harorlı A. Antral retansiyon kistinin radyolojik tespiti; dental volümetrik tomografi ile waters pozisyonunda çekilen paranazal sinüs radyogramın karşılaştıııması. Atatürk Üniv Diş Hek Fak Derg 2011;21: 63-7

16. Hickner JM, Bartlett JG, Besser RE, Gonzales R, Hoffman JR, Sande MA. Principles of appropriate antibiotic use for acute rhinosinusitis in adults: background. Annals of Internal Medicine 2001;134: 498-505. 
17. De Sutter A, Spee R, Peersman W, De Meyere M, Van Cauwenberge $P$, Verstraete $K$, et al. Study on the reproducibility of the Waters' views of the maxillary sinuses. Rhinology 2005;43:55-60.

18. Srinivasa Prasad T, Sujatha G, Niazi TM, Rajesh P. Dentigerous cyst associated with an ectopic third molar in the maxillary sinus: a rare entity. Indian journal of dental research : official publication of Indian Society for Dental Research 2007;18:141-3.

19. Bhaskar SN. Synopsis of oral pathology: Mosby; 1986.

20. Tournas AS TM, Chauvin PJ, Manoukian JJ. Multiple unilateral maxillary dentigerous cysts in a nonsyndromic patient: a case report and review of the literature. Int J Pediatr Otorhinolaryngol Extra 2006;1:100-6.

21. Golden AL, Foote J, Lally E, Beideman R, Tatoian J. Dentigerous cyst of the maxillary sinus causing elevation of the orbital floor. Report of a case. Oral surgery, oral medicine, and oral pathology 1981;52:133-6.

22. Smith JL, Kellman RM. Dentigerous cysts presenting as head and neck infections. Otolaryngology-Head and Neck Surgery 2005; 133 : 715-17.

23. Martinez-Perez D, Varela-Morales M. Conservative treatment of dentigerous cysts in children: a report of 4 cases. Journal of Oral and Maxillofacial Surgery : Official Journal of the American Association of Oral and Maxillofacial Surgeons 2001;59:331-3.

24. Litvin M, Caprice D, Infranco L. Dentigerous cyst of the maxilla with impacted tooth displaced into orbital rim and floor. Ear, Nose, \& Throat Journal 2008;87:160-2.

25. DeFreitas J, Lucente FE. The Caldwell-Luc procedure: institutional review of 670 cases: 19751985. The Laryngoscope 1988;98:1297-300.

26. Bailey BJ, Johnson JT, Newlands SD. Head \& neck surgery-otolaryngology: Lippincott Williams \& Wilkins; 2006.

27. Hollinshead WH. The nose and paranasal sinuses. In: Hollinshead WH, editor. Anatomy for Surgeons: The Head and Neck. Philadelphia: Lippincott Williams \& Wilkins; 1982. p. 259-63.

28. Hilding A. Experimental sinus surgery: effects of operative windows on normal sinuses. Ann Otol Rhinol Laryngol 1941;50:379-92.

\author{
Yazışma Adresi \\ Nesrin SARUHAN \\ Atatürk Üniversitesi, Diş Hekimliği Fakültesi \\ Ağız, Diş ve Çene Cerrahisi A D Erzurum \\ Fax: 0904422360945 \\ TIf: 0904422311747 , \\ e-mail: dt_nesrin@yahoo.com
}

